\title{
A clinicomicrobial study of diabetic foot ulcer infections in South India
}

$\frac{\pi}{0}$

\section{Ranjini Chittur Yerat, Vidhya Rani Rangasamy ${ }^{1}$}

Department of Microbiology, Vydehi Institute of Medical Sciences and Research Centre, Whitefield, Bengaluru, Karnataka,

${ }^{1}$ Department of Microbiology, Government Dharmapuri Medical College, Dharmapuri, Tamil Nadu, India

Address for the Correspondence: Dr. Ranjini Chittur Yerat, A G 11, DSR Sunshine Apartments, Krishna Reddy Layout, $1^{\text {st }}$ Main, Banaswadi, Bengaluru - 560 043, Karnataka, India.

E-mail: ranju.prabhu@gmail.com

\begin{tabular}{|l|}
\hline Access this article online \\
\hline Website: www.ijmedph.org \\
\hline DOI: $10.4103 / 2230-8598.161545$ \\
\hline Quick response code:
\end{tabular}

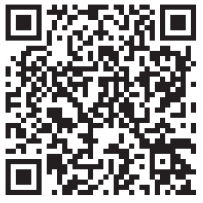

Background: Approximately $85 \%$ of all diabetes-related lower-extremity amputations are preceded by foot ulcers. Diabetic foot ulcers are at high risk of infection secondary to high glucose levels and poor tissue perfusion. Aims of the Study: To identify the microbial pathogens and the antimicrobial sensitivity pattern of the bacterial isolates involved in the different grades of diabetic foot ulcers. Materials and Methods: Pus samples from 104 diabetic foot ulcers were processed for aerobic, anaerobic, and fungal culture. Antimicrobial sensitivity was performed as per clinical and laboratory Standards Institute guidelines. Results: Aerobic (81.66\%), anaerobic $(14.79 \%)$, and fungal $(3.55 \%)$ isolates were obtained on culture with Gram-negative bacilli $(78.98 \%)$ being isolated more than the Gram-positive cocci (21.01\%). Proteus mirabilis was the most common isolate $(26.08 \%)$ while Bacteroides fragilis and Peptococcus sp. were the common anaerobes obtained. $56.73 \%$ of patients had polymicrobial infection, and $23.08 \%$ of staphylococci were methicillin resistant Staphylococcus aureus. In hospitalized patients and amputees, infections were often polymicrobial $(74.32 \%)$ involving anaerobic and fungal pathogens. Multi-drug resistance was seen in $28.26 \%$ of isolates. Conclusion: Our study showed polymicrobial diabetic foot infections. The isolation pattern varied according to the grade of ulcer with $S$. aureus being predominant in Wagner I diabetic foot and Gram-negative organisms and anaerobes being isolated as the foot grade advanced to gangrene. Management of early stages includes treatment with oral quinolones/cloxacillin/cephalosporins. Imipenem monotherapy or third-generation cephalosporins with beta lactamase inhibitors plus an anti-anaerobe drug are regimens that can be used for the advanced stage of the disease.

Key words: Amputation, anaerobes, Gram-negative bacilli, polymicrobial

\section{INTRODUCTION}

Diabetes mellitus with its multisystem affliction has emerged as the scourge of the $21^{\text {st }}$ century. About 370 million people are affected with diabetes mellitus globally, and the numbers are estimated to reach 552 million by $2030 .{ }^{[1]}$ About $15 \%$ of diabetics develop foot ulcers during their lifetime, and this constitutes the most common cause of disability and hospitalization. ${ }^{[2]}$ Limb-threatening diabetic infections are usually polymicrobial involving multiple aerobic and anaerobic organisms. Staphylococcus aureus, Streptococcus spp., Enterobacteriaceae spp., Bacteroides fragilis, Peptococcus spp. and Peptostreptococcus spp. are the common organisms cultured from diabetic ulcers. ${ }^{[3]}$ Proper choice of antimicrobials in the treatment of a limb-threatening diabetic foot ulcer infection is imperative in preventing amputation.

\section{Aim of the study}

This study was undertaken to identify the aerobic, anaerobic, and fungal pathogens involved in the different grades of diabetic foot ulcers and to find out the antimicrobial sensitivity pattern of the bacterial isolates.

\section{MATERIALS AND METHODS}

Pus samples were taken from 104 patients with diabetic foot ulcer which comprised of 30 outpatients and 74 inpatients. The patients were clinically assessed and history regarding the duration of diabetes, 
smoking, alcohol intake, trauma preceding the ulcer, previous history of ulcer or amputation, duration of stay in the hospital, associated medical illnesses such as ischemic heart disease or renal disease, glycemic control status, the use of oral hypoglycemics/insulin and antibiotics used was taken. Physical examination included inspection of the foot ulcer and musculoskeletal examination for any foot deformity. The location, size, depth, margin, color, grade of the ulcer, presence of granulation tissue, necrotic tissue, edema, erythema, foul odor, and purulent discharge were noted. The ulcers were graded based on the Megitt Wagner classification which categorizes diabetic foot ulcers into five grades on the basis of anatomical location, depth, and presence of ischemia. ${ }^{[4]}$

\section{Disease definition}

Diabetic foot infection was defined as the presence of a nonhealing wound with evidences of inflammation, with or without systemic toxicity, and with a definite growth on culture that correlated with the Gram's stain.

\section{Sample collection}

The ulcer site and size were examined, and the superficial dead tissue was removed with sterile scissors. After local debridement of devitalized tissue, the ulcer wound was scrubbed thoroughly with normal saline to remove surface colonizers. Sample collection was then done using sterile cotton swabs for all cases. Scrapings of the ulcer base were collected in a sterile manner where necrotic tissue was present. Pus aspirates where appropriate (presence of any deep abscess) and two swabs were collected, one for Gram-stain and the other for aerobic culture. Anaerobic isolation was done when clinically suspected and for this the overlying and adjacent areas were carefully disinfected with $70 \%$ ethanol to eliminate contamination with indigenous flora. When swabs and tissue scrapings were collected, they were immediately inoculated into the transport media. In deep abscesses, pus was obtained by needle aspiration, the tip of which was immediately plunged into a sterile rubber cork to prevent air exposure.

\section{Transportation of samples}

Samples were taken immediately to the laboratory. Specimens meant for anaerobic processing were transported in brain heart infusion agar (BHIA) with $0.1 \%$ agar base.

\section{Microscopic examination}

The type and relative number of microorganisms and host cells were identified by a direct Gram-stain smear of all the samples.

\section{Aerobic culture}

The specimens were cultured on blood agar and MacConkey agar plates for aerobic culture and incubated at $37^{\circ} \mathrm{C}$ for $48 \mathrm{~h}$. The bacterial isolates were then identified, and antimicrobial sensitivity performed by the standard microbiological techniques as per the Clinical and laboratory Standards Institute guidelines. ${ }^{[5]}$

\section{Anaerobic culture}

Anaerobic culture was done by inoculation of specimens immediately on sampling into Robertson's cooked meat broth and BHIA in $0.1 \%$ agar topped with paraffin wax. The tubes were immediately overlaid with sterile liquid paraffin and transported to the lab without delay. Level I identification included information from the primary plates in conjunction with Gram-stain and colony morphology. Level II identification was based on colony and cell morphology, Gramstain, susceptibility to antibiotic identification discs and nitrate reduction disc test done on the purity plate. ${ }^{[6]}$ The sample was inoculated onto $5 \%$ sheep blood agar plates supplemented with Vitamin $\mathrm{k} 1(10 \mu \mathrm{g} / \mathrm{ml})$ and Hemin $(5 \mu \mathrm{g} / \mathrm{ml})$ and Gentamicin $20 \mu \mathrm{g} / \mathrm{ml}$, and Bacteroides Bile Esculin Agar as the selective medium for identification of $B$. fragilis [Figure 1]. Incubation was done in anaerobic Gaspak jar at $35-37^{\circ} \mathrm{C}$ for $48 \mathrm{~h}$. Reduced methylene blue was used as the indicator. After incubation, the primary plates were examined for colony morphology, hemolysis, and pigmentation. The individual colonies were identified by Gram-stain and subcultured to the purity blood agar plate. The following antibiotic discs were placed on the first quadrant of the purity plate. Vancomycin $5 \mu \mathrm{g}$, kanamycin $1000 \mu \mathrm{g}$ and colistin sulfate $10 \mu \mathrm{g}$. Metronidazole $5 \mu \mathrm{g}$ discs and nitrate discs were placed in the second quadrant. The plates were then incubated anaerobically as mentioned above for $48 \mathrm{~h}$ at $35^{\circ} \mathrm{C}$.

\section{Fungal culture}

Fungal isolates were identified by inoculation into Sabouraud's dextrose agar and incubated at $25^{\circ} \mathrm{C}$ and $37^{\circ} \mathrm{C}$ for $3-4$ weeks.

\section{Blood culture}

In patients with clinical signs of sepsis blood culture was done.

\section{Antibiotic sensitivity}

Antibiotic sensitivity was performed on Mueller Hinton agar plates by the Kirby Bauer disc diffusion method using antibiotic discs obtained from HI MEDIA, Mumbai. The antibiotics used for

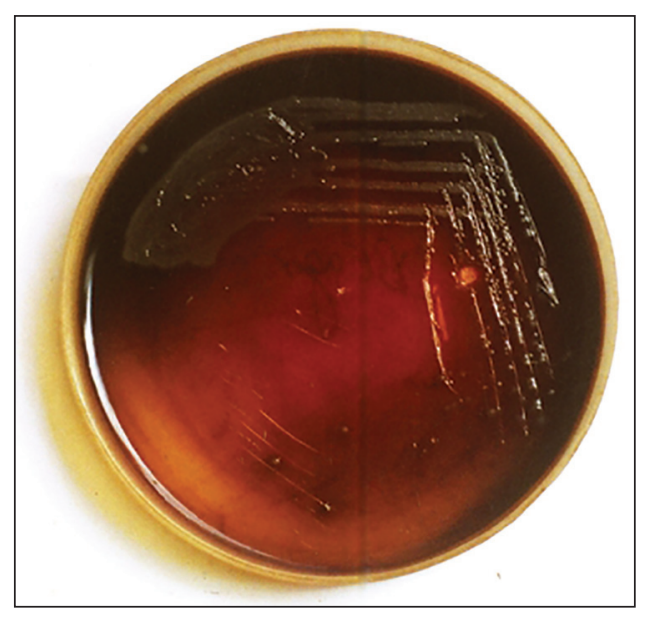

Figure 1: Bile Esculin hydrolysis of Bacteroides fragilis on Bacteroides bile esculin agar 
Gram-positive organisms were Penicillin G (P-10 U), Oxacillin (Oxa-1 $\mu \mathrm{g}$ ), Erythromycin (E-25 $\mu \mathrm{g}$ ), Ampicillin (Amp-10 $\mu \mathrm{g}$ ), Ampicillin-Sulbactam (AS-10/10 $\mu \mathrm{g}$ ), Ceftazidime (Caz-30 $\mu \mathrm{g}$ ), Cefoperazone $(\mathrm{Cs}-75 \mu \mathrm{g})$, Ofloxacin (Of-5 $\mu \mathrm{g}$ ) and Vancomycin (Va-30 $\mu \mathrm{g})$. The antibiotics employed for Gram-negative bacteria were Amikacin (Ak-30 $\mu \mathrm{g})$, Gentamicin (G-10 $\mu \mathrm{g})$, Ofloxacin (Of-5 $\mu \mathrm{g}$ ), Ceftazidime (Caz-30 $\mu \mathrm{g}$ ), Cefoperazone (Cs-30 $\mu \mathrm{g}$ ), Cefoperazone-Sulbactam (Cfs-75/30 $\mu \mathrm{g}$ ), Piperacillin (Pip-100 $\mu \mathrm{g}$ ), Cotrimoxazole (Co-25 $\mu \mathrm{g}$ ), and Imipenem (I-10 $\mu \mathrm{g})$. B-lactamase detection in Staphylococcus sp. was done by the iodometric method.

\section{RESULTS}

The demographic profile of our patients showed that males $(60.57 \%)$ were more commonly affected than females $(39.42 \%)$ and the male:female ratio was 1.53:1. Majority of our patients were in the 50 to 60 age group (44.23\%). The mean age was 54.93 years (standard deviation $=10.926) .93 .26 \%$ of our patients had type 2 diabetes. Trauma $(33.65 \%)$ and smoking $(30.76 \%)$ were the most common risk factors, followed by alcohol intake and previous ulcer. None of the risk factors assessed were significant $(P>0.05)$ for the development of foot ulcer [Table 1].

Neuropathy was seen in $67.30 \%$ of patients while impaired vascularity was seen in 27 patients $(25.96 \%)$. Nine patients $(12.16 \%)$ had purely ischemic while 18 (24.32\%) had neuro-ischemic ulcers. Coronary heart disease and hypertension were present in eight patients each while renal dysfunction was present in five patients.

Seven patients presented with systemic signs of fever of whom three were blood culture positive. All three of them had grade four ulcer and underwent amputation. Majority of the patients had grade 4 ulcers $(40.38 \%)$.

Regarding the microbial isolates from the 104 pus samples, we isolated 163 bacterial and 6 fungal organisms. Gram-negative bacilli (GNBs) (78.98\%) were isolated more than the Gram-positive cocci (GPCs) (21.01\%) [Table 2]. Proteus mirabilis was the most common isolate $(21.30 \%)$. S. aureus was the most common GPCs isolated $(12.43 \%)$. Anaerobes constituted $14.79 \%$ of the total isolates. B. fragilis and Peptococcus sp. were the common anaerobes obtained. Clostridium tetani was isolated from a patient with grade 3 ulcer. Maximum isolation of anaerobes was from grade 5 while GPC and GNBs were obtained more from grade 1 and grade 2 ulcers, respectively [Table 3]. Regarding the antimicrobial sensitivity pattern, we found that $57.14 \%$ of $S$. aureus were beta lactamase producer and 5 of the 21 isolates were methicillin-resistant $S$. aureus (MRSA) (23.80\%). The GPC isolates were 100\% sensitive to vancomycin while all the Gram-negative bacterial isolates were 100\% sensitive to imipenem [Table 4].

\section{DISCUSSION}

Foot ulcer is one of the most feared complications in persons with diabetes. $50 \%$ of all Lower Extremity Amputations

\begin{tabular}{|c|c|c|}
\hline Risk factors & $n=104$ & Percentage \\
\hline Smoker & 32 & 30.76 \\
\hline Alcoholic & 24 & 23.07 \\
\hline Trauma & 35 & 33.65 \\
\hline Previous ulcer & 16 & 15.38 \\
\hline Prior amputation & 6 & 5.76 \\
\hline Previous ulcer leading to amputation & 9 & 8.65 \\
\hline \multicolumn{3}{|l|}{ Type of diabetes } \\
\hline Type 1 & 7 & 6.73 \\
\hline Type 2 & 97 & 93.26 \\
\hline \multicolumn{3}{|l|}{ Neuropathy } \\
\hline Mild & 39 & 37.5 \\
\hline Moderate & 29 & 27.88 \\
\hline Severe & 2 & 1.92 \\
\hline No neuropathy & 34 & 32.69 \\
\hline Vascular assessment & $n=74$ & Percentage \\
\hline Ischemic & 9 & 12.16 \\
\hline Neuroischemic & 18 & 24.32 \\
\hline Normal vascularity & 41 & 55.40 \\
\hline Medications & $n$ & Percentage \\
\hline $\mathrm{OHA}$ & 42 & 40.38 \\
\hline Insulin & 26 & 25 \\
\hline Fever & 7 & 6.73 \\
\hline Leukocytosis & 3 & 2.88 \\
\hline \multirow[t]{2}{*}{ Blood culture } & 3 & 2.88 \\
\hline & $n$ & SD \\
\hline Mean duration of diabetes (years) & 7.14 & 3.71 \\
\hline Mean RBS (mg/dl) & 190.88 & 46.1 \\
\hline
\end{tabular}

\begin{tabular}{llc} 
Table 2: Type and frequency of organisms isolated \\
\hline $\begin{array}{l}\text { Type of organism } \\
(\boldsymbol{n}=169)\end{array}$ & Organism isolated & $\begin{array}{c}\text { Frequency } \\
\boldsymbol{n}(\%)\end{array}$ \\
\hline GPC $(n=29)$ & Staphylococcus aureus & $21(12.43)$ \\
& Enterococcus faecalis & $8(4.73)$ \\
GNB $(n=109)$ & Proteus mirabilis & $36(21.30)$ \\
& Escherichia coli & $25(14.79)$ \\
& Pseudomonas aeruginosa & $17(10.06)$ \\
& Klebsiella pneumonia & $13(7.69)$ \\
& Morganella morganii & $9(5.33)$ \\
& Proteus vulgaris & $5(2.96)$ \\
& Klebsiella oxytoca & $1(0.43)$ \\
& Proteus penneri & $1(0.43)$ \\
& Citrobacter koseri & $1(0.43)$ \\
Anaerobes $(n=25)$ & Acinetobacter baumanii & $1(0.43)$ \\
& Bacteroides fragilis & $8(4.73)$ \\
& Peptococcus species & $8(4.73)$ \\
& Peptostreptococcus species & $5(2.95)$ \\
Fungi $(n=6)$ & Clostridium welchii & $3(1.77)$ \\
& Clostridium tetani & $1(0.59)$ \\
& Candida albicans & $5(2.96)$ \\
& Nonalbicans Candida species & $1(0.59)$ \\
\hline
\end{tabular}

$\mathrm{GPC}=$ Gram positive cocci, GNB = Gram negative bacilli

(LEA) are diabetes related ${ }^{[7]}$ with infection occurring as the second most frequent indication, next to gangrene for diabetic LEA. 
In this study, there were a total of 169 isolates [Table 2]. The isolation rate of Gram-negative bacteria was higher compared to the GPCs depicting a ratio of 3.75:1. Many studies have been done on the microbial analysis of diabetic foot ulcers with varying results on the etiological agents in different regions. ${ }^{\left[{ }^{8,9]}\right.}$ In a study done in North India, Tiwari et al. ${ }^{[10]}$ also had found higher incidence of aerobic Gram-negative bacterial infections. In Carvalho study ${ }^{[11]}$ also the most frequently occurring pathogens in diabetic foot were members of Enterobacteriaceae (83.7\%).

In contrast, many other studies have shown a predominance of S. aureus over Gram-negative bacterial isolates. ${ }^{[12,13]}$ This may be linked to the difference in sample collection methodologies, duration and depth of ulcer wound and the glycemic status. ${ }^{[14]}$ Gardner et al. had found that the ulcer duration and depth correlated positively with an increase in Proteobacterial isolates and negatively with the yield of Staphylococci by culture. ${ }^{[15]}$

Among the GNBs, P. mirabilis was the most common isolate followed by Escherichia coli, S. aureus, Pseudomonas aeruginosa, Klebsiella pneumoniae, Morganella morganii, and Enterococcus spp. This is similar to the pattern obtained by Gadepalli et al. ${ }^{[16]}$

\begin{tabular}{|c|c|c|c|c|}
\hline \multirow[t]{2}{*}{ Ulcer grade } & GPC & GNB & Anaerobes & $\begin{array}{c}\text { Total } \\
(n=163)\end{array}$ \\
\hline & $\begin{array}{c}\text { Number } \\
(\%)\end{array}$ & $\begin{array}{c}\text { Number } \\
(\%)\end{array}$ & $\begin{array}{c}\text { Number } \\
(\%)\end{array}$ & $\begin{array}{c}\text { Number } \\
(\%)\end{array}$ \\
\hline Grade $1(n=22)$ & $7(31.81)$ & $15(68.18)$ & $0(0)$ & $22(13.49)$ \\
\hline Grade $2(n=19)$ & $3(15.78)$ & $16(84.21)$ & $0(0)$ & 19 (11.65) \\
\hline Grade $3(n=36)$ & $7(19.44)$ & $24(66.66)$ & $5(13.88)$ & $36(22.08)$ \\
\hline Grade $4(n=75)$ & $11(14.66)$ & $50(66.66)$ & $14(18.66)$ & $75(46.01)$ \\
\hline Grade $5(n=11)$ & 1 (9.09) & $4(36.36)$ & $6(54.54)$ & $11(6.74)$ \\
\hline$n=163$ & 29 (17.79) & $109(66.87)$ & $25(15.33)$ & $163(100)$ \\
\hline
\end{tabular}

We isolated 25 anaerobes in culture of which $B$. fragilis and Peptococcus spp. were the common organisms. Other isolates include Peptostreptococcus sp. (5), Clostridium welchii (3) and C. tetani (1) [Figure 2]. In Unachukwu's study aerobes and anaerobes constituted $95.4 \%$ and $4.6 \%$ of the total bacterial isolates, respectively ${ }^{[17]}$ All the anaerobes were $100 \%$ sensitive to metronidazole in our study. In a study on antibiotic sensitivity of anaerobes in diabetic foot ulcers, $\mathrm{Ng}$ et al. had also found $98 \%$ sensitivity to imipenem and $99 \%$ sensitivity to metronidazole. ${ }^{[18]}$ We found that BHIA with $0.1 \%$ agar gave a better isolation rate of the anaerobes compared to Robertson's Cooked Meat broth.

Fungal organisms comprised only $3.55 \%$ of the total isolates. Candida albicans was the most common isolate (83.33\%). Missoni et al. ${ }^{[19]}$ had also reported a low incidence of Candida infections in diabetic foot ulcers (4.3\%). In a study by Chincholikar and $\mathrm{Pal}$ Candida albicans was the most common fungal pathogen. ${ }^{20]}$

Anaerobic (24/25 isolates) and fungal infection was also seen predominantly among hospitalized patients only. Most of these patients had limb-threatening infection. Thus, infection severity appears related to number and type of infecting organism.

In general, diabetic foot ulcers have a polymicrobial infection though Raymundo and Mendoza had reported more mono microbial isolation (54\%). ${ }^{[21]}$ This may be attributed to prior antibiotic therapy before wound sampling. In our study, $38.46 \%$ of patients had antimicrobial isolates, and $56.73 \%$ of patients had polymicrobial infection. An average of 1.629 organisms was isolated per specimen in this study compared to Sharp et al. ${ }^{[22]}$ who obtained an average of 2.3 organisms per specimen. The relatively low isolation rate may be due to the lesser isolation of anaerobes as the competency to isolate all the species of anaerobic organisms was not yet maximized in our study.

We found that mono microbial infection was seen more among out-patients $(76.66 \%)$ while, in hospitalized patients $(74.32 \%)$ and

\begin{tabular}{|c|c|c|c|c|c|c|c|c|c|c|}
\hline \multirow{2}{*}{$\begin{array}{l}\text { Organism } \\
\text { GPC }\end{array}$} & \multicolumn{10}{|c|}{ Antibiotic sensitivity in \% } \\
\hline & $\mathbf{P}$ & Amp & CAZ & Oxa & As & Cfs & Of & $E$ & Va & \\
\hline Staphylococcus aureus & 0 & 14.29 & 76.19 & 76.19 & 76.19 & 76.19 & 66.67 & 9.52 & 100 & \\
\hline Enterococcus faecalis & 0 & 50 & - & - & 100 & - & 62.5 & 37.5 & 100 & \\
\hline GNB & Co & Amp & $\mathrm{Caz}$ & Pip & Cs & Cfs & Of & G & Ak & $\mathbf{I}$ \\
\hline Escherichia coli (25) & 8 & 8 & 60 & 40 & 24 & 88 & 24 & 40 & 84 & 100 \\
\hline Klebsiella pneumoniae (13) & 7.69 & 7.69 & 76.92 & 69.23 & 61.53 & 92.30 & 84.61 & 69.23 & 84.61 & 100 \\
\hline Klebsiella oxytoca (1) & 0 & 0 & 0 & 100 & 0 & 100 & 100 & 0 & 100 & 100 \\
\hline Citrobacter koseri (1) & 0 & 0 & 0 & 100 & 0 & 100 & 100 & 100 & 100 & 100 \\
\hline Proteus mirabilis (36) & 16.66 & 33.33 & 33.33 & 19.44 & 16.66 & 88.88 & 38.88 & 19.44 & 47.22 & 100 \\
\hline Proteus vulgaris (5) & 0 & 20 & 60 & 20 & 40 & 100 & 60 & 20 & 60 & 100 \\
\hline Proteus penneri (1) & 0 & 0 & 0 & 0 & 100 & 100 & 0 & 0 & 100 & 100 \\
\hline Morganella morganii (9) & 22.22 & 22.22 & 66.66 & 22.22 & 44.44 & 98.69 & 66.66 & 22.22 & 55.55 & 100 \\
\hline Pseudomonas aeruginosa (17) & 5.88 & 35.29 & 52.94 & 88.23 & 52.94 & 88.23 & 58.82 & 35.29 & 52.94 & 100 \\
\hline Acinetobacter baumanii (1) & 0 & 0 & 0 & 0 & 0 & 100 & 0 & 0 & 0 & 100 \\
\hline
\end{tabular}

$\mathrm{P}=$ Penicillin, Amp = Ampicillin, Oxa = Oxacillin, Cfs = Cefaperazone sulbactam, Caz = Ceftazidime, Of = Ofloxacin, Vancomycin, E = Erythromycin, As = Ampicillin sulbactam, $\mathrm{Co}=$ Cotrimoxazole. I = Imipenem, Cs = cefaperazone, Pip = Pipericillin tazobactam, G = Gentamicin, Ak = Amikacin, GPC= Gram positive cocci, GNB = Gram negative bacilli 
patients who progressed to amputation $(66.66 \%)$, infections were often polymicrobial. The ratio of polymicrobial: Mono-microbial infection was 3:2. In amputees it was 2.4:1 while in the nonamputees group it was 1.2:1 [Chart 1]. Polymicrobial infection have important clinical implication in that the multiple organisms tend to form biofilms which impedes the activity of antimicrobial agents. ${ }^{[23]}$ Furthermore, the interaction among the organisms leads to release of virulence factors and agents which increase inflammation and act synergistically to cause a chronic wound infection. ${ }^{[14,23]}$ Dowd et al. have hypothetized that certain bacterial species act symbiotically to form functional equivalent pathogroups (FEPs). These FEPs form a pathogenic biofilm which in turn promotes the chronicity of the wound. ${ }^{[2]}$

While studying the variation in the type of organisms in different grade of foot ulcers, our work showed that GNBs (45.87\%) were predominant in all the grade of foot ulcers [Figure 3]. GPC was found in higher $\%$ in grade 1 ulcer. They formed $31.81 \%$ of the total isolates in Grade 1 ulcer and were found in $<20 \%$ of the total isolate in the other grades of foot ulcer. Maximum isolation of all organisms was seen in grade 4 ulcers (46.01\%). Anaerobic isolation rate also increased with grade of the ulcer [Table 3].

Tentolouris et al. ${ }^{[25]}$ had reported that $S$. aureus was the most prevalent pathogen of Gram-positive aerobes isolated from wounds and MRSA organisms comprised $40 \%$ of $S$. aureus isolates. They also found that MRSA infection or colonization was not associated with factors like previous hospitalization, use of antibiotics, etc., that are known to predispose to MRSA colonization or infection. MRSA isolates formed $23.80 \%$ of the isolates in our study.

The sensitivity pattern of the Gram-negative isolates revealed $100 \%$ sensitivity to Imipenem and around 90\% sensitivity to Cefoperazone-Sulbactam [Table 4]. The Enterobacteriaceae was better sensitive to aminoglycosides and quinolones than the third-generation cephalosporins. While Citrobacter spp. was 100\% sensitive to amikacin, E. coli and Klebsiella spp. showed a sensitivity of $84 \%$ and $84.61 \%$, respectively, to amikacin. Klebsiella spp. was equally sensitive to ofloxacin (84.61\%). Proteus species exhibited moderate to poor sensitivity to all the drugs. A study by Anandi et al. ${ }^{[26]}$ had also shown that E. coli $(97 \%)$ and Klebsiella spp. (94\%) were sensitive to ciprofloxacin and ofloxacin and all aerobes were sensitive to Amikacin. Pseudomonas spp. was highly sensitive to Pipericillin and poorly sensitive to all the other antibiotics. Acinetobacter sp. was resistant to all drugs except imipenem. All the isolates were poorly sensitive to cotrimoxazole $(<25 \%)$.

Multi drug resistance was seen in $28.26 \%$ of the organisms predominantly occurring in Acinetobacter sp. (100\%), Klebsiella sp. $(50 \%)$ and Proteus species (41.66\%). All the patients had $\geq$ grade 3 ulcers. In a study conducted by Hartemann-Heurtier et al., ${ }^{[27]}$ it was found that multidrug-resistant organisms (MDROs) are often present in severe diabetic foot wounds. They found that about one-third of patients with a history of previous hospitalization for the same wound, and $25 \%$ of patients with osteomyelitis had MDRO-positive specimens.

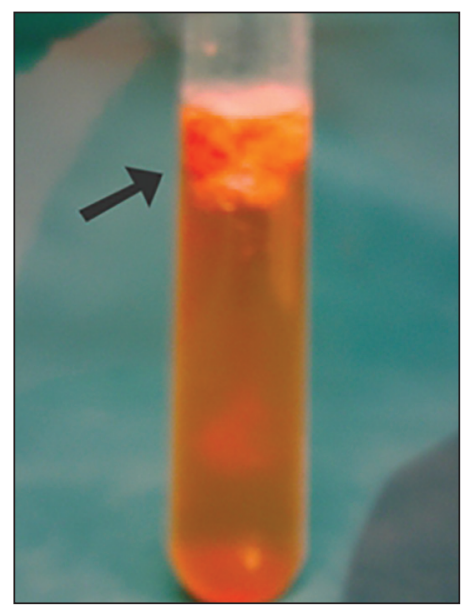

Figure 2: Stormy fermentation of Clostridium perfringens-the meat particle is pushed upwards

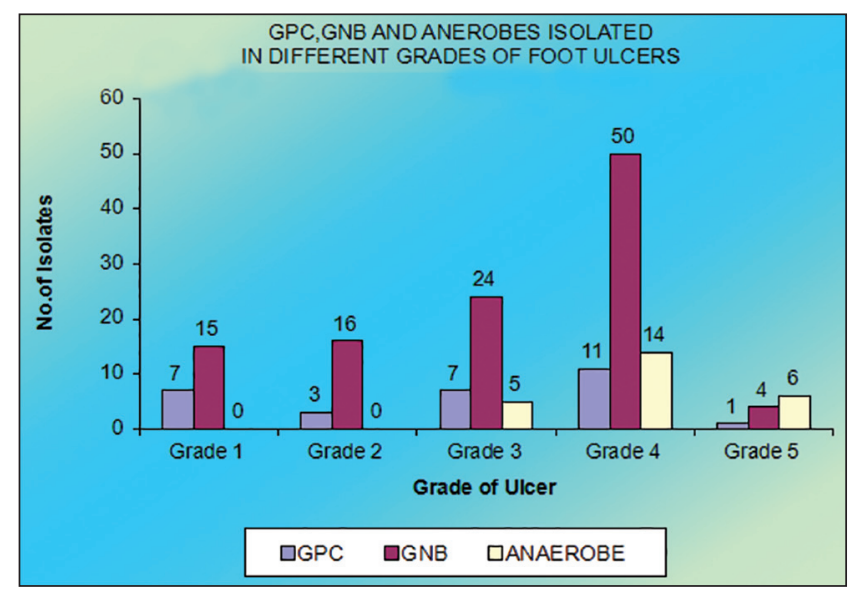

Figure 3: Organisms isolated in different grades of foot ulcers

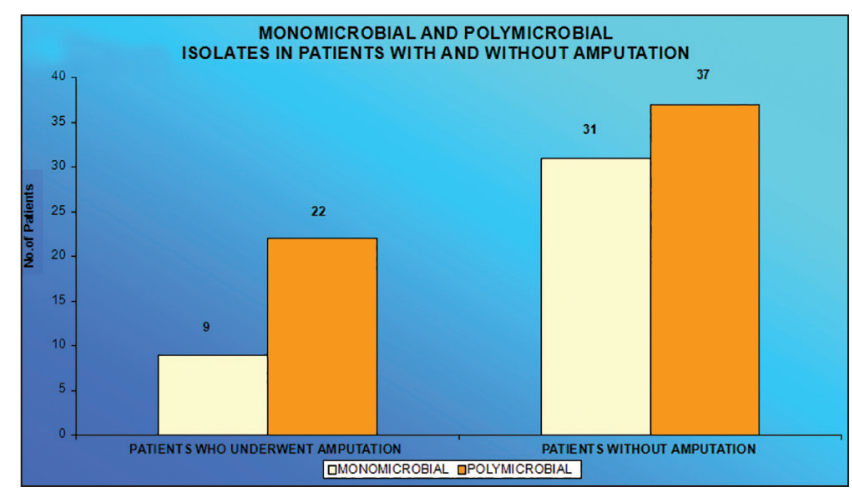

Chart 1: Mono microbial and polymicrobial infection in patients with and without amputation

\section{CONCLUSION}

Our study showed polymicrobial diabetic foot infections with Gramnegative aerobes being the most common pathogens. The isolation pattern varies according to the grade of ulcer. $S$. aureus were predominant in Wagner grade I diabetic foot while Gram-negative organisms, majority of which were P. mirabilis sp. and E. colisp., were isolated as the foot grade 
advanced to gangrene. Furthermore, significant anaerobic growth was observed in Wagner's IV and V lesions. Hence, a polymicrobial growth with GNBs and presence of anaerobes should be aggressively managed.

Prompt initiation of appropriate antibiotic therapy, as well as surgical debridement of necrotic or de vascularized soft tissue and bone are essential for controlling the infection and preventing additional morbidity. Culture and sensitivity results should be followed-up as early as possible and antimicrobial coverage should be adjusted accordingly. Based on our antimicrobial susceptibility pattern, as GPCs are predominant in the early stages treatment with oral quinolones/cloxacillin/cephalosporins is advisable. Aminoglycosides, Cefoperazone-Sulbactam, and quinolones were found to be effective in Gram-negative infections while metronidazole still remained the drug of choice for anaerobes. Imipenem monotherapy or third-generation cephalosporins with beta lactamase inhibitors along with metronidazole are the preferred regimens for the advanced stage of the disease.

\section{ACKNOWLEDGMENT}

We are greatly indebted to Dr. T.S. Vijayalakshmi and Dr. Sujatha Varadarajan for their valuable guidance and support.

\section{REFERENCES}

1. International Best Practice Guidelines: Wound Management in Diabetic Foot Ulcers. Wounds international; 2013. Available from: http://www. woundsinternational.com. [Last accessed on 2015 Mar 3].

2. Singh N, Armstrong DG, Lipsky BA. Preventing foot ulcers in patients with diabetes. JAMA 2005;293:217-28.

3. Lipsky BA, Berendt AR, Cornia PB, Pile JC, Peters EJ, Armstrong DG, et al. 2012 Infectious Diseases Society of America clinical practice guideline for the diagnosis and treatment of diabetic foot infections. Clin Infect Dis 2012;54:e132-73.

4. Wagner FW. Algorithms of diabetic foot care. In: Levin ME, Oneal FW, editors. The Diabetic Foot. St. Louis: CV Mosby Co.; 1983. p. 29.

5. CLSI. Performance standards for antimicrobial susceptibility testing; Twenty second informational supplement. CLSI document M100-S22. Wayne, PA: Clinical and Laboratory Standards Institute; 2012.

6. Forbes BA, Sahm DF, Weissfeld AS, editors. Anaerobic bacteriology. In: Bailey and Scott's Diagnostic Microbiology. $12^{\text {th }}$ ed. St. Louis: Mosby; 2007. p. 455-77.

7. Abdulrazak A, Bitar ZI, Al-Shamali AA, Mobasher LA. Bacteriological study of diabetic foot infections. J Diabetes Complications 2005;19:138-41.

8. Halpati A, Desai KJ, Jadeja R, Parmar M. A study of aerobic and anaerobic bacteria in diabetic foot ulcer and in vitro sensitivity of antimicrobial agent. Int J Med Sci Public Health 2014;3:818-21.

9. Rouhipour N, Hayatshahi A, Nikoo MK, Yazdi NM, Heshmat R, Qorbani M, et al. Clinical microbiology study of diabetic foot ulcer in Iran; pathogens and antibacterial susceptibility. Afr J Microbiol Res 2012;6:5601-8.
10. Tiwari S, Pratyush DD, Dwivedi A, Gupta SK, Rai M, Singh SK. Microbiological and clinical characteristics of diabetic foot infections in northern India. J Infect Dev Ctries 2012;6:329-32.

11. Carvalho CB, Neto RM, Aragão LP, Oliveira MM, Nogueira MB, Forti AC. Diabetic foot infection. Bacteriologic analysis of 141 patients. Arq Bras Endocrinol Metabol 2004;48:398-405.

12. Chopdekar KA, Joshi AA, Shivram S, Bharadwaj RS, Mukadam IS, Hulyalkar VS, et al. Bacteriological analysis of diabetic foot infection. Bombay Hosp J 2011;53:706-11.

13. Citron DM, Goldstein EJC, Merriam V, Lipsky BA, Abramson MA Bacteriology of Moderate-to-Severe Diabetic Foot Infections and In Vitro Activity of Antimicrobial Agents. J Clin Microbiol 2007:45:2819-28.

14. Lipsky BA, Richard JL, Lavigne JP. Diabetic foot ulcer microbiome: One small step for molecular microbiology. One giant leap for understanding diabetic foot ulcers? Diabetes 2013;62:679-81.

15. Gardner SE, Hillis SL, Heilmann K, Segre JA, Grice EA. The neuropathic diabetic foot ulcer microbiome is associated with clinical factors. Diabetes 2013;62:923-30.

16. Gadepalli R, Dhawan B, Sreenivas V, Kapil A, Ammini AC, Chaudhry R. A clinico-microbiological study of diabetic foot ulcers in an Indian tertiary care hospital. Diabetes Care 2006;29:1727-32.

17. Unachukwu CN, Obunge OK, Odia OJ. The bacteriology of diabetic foot ulcers in Port Harcourt, Nigeria. Niger J Med 2005;14:173-6.

18. Ng LS, Kwang LL, Yeow SC, Tan TY. Anaerobic culture of diabetic foot infections: Organisms and antimicrobial susceptibilities. Ann Acad Med Singapore 2008;37:936-9.

19. Missoni EM, Kalenic S, Vukalic M, Syo DD, Becliza M, Babic VV. Candida infections of diabetic foot ulcers. Diabetol Croat 2005;34:29-34.

20. Chincholikar DA, Pal RB. Study of fungal and bacterial infections of the diabetic foot. Indian J Pathol Microbiol 2002;45:15-22.

21. Raymundo MF, Mendoza MT. The microbiologic features and clinical outcome of diabetic foot infections among patients admitted at UP-PGH. Philipp J Microbiol Infect Dis 2002;31:51-63.

22. Sharp CS, Bessman AN, Wagner FW Jr, Garland D. Microbiology of deep tissue in diabetic gangrene. Diabetes Care 1978;1:289-92.

23. Citron DM, Goldstein EJ, Merriam CV, Lipsky BA, Abramson MA Bacteriology of moderate-to-severe diabetic foot infections and in vitro activity of antimicrobial agents. J Clin Microbiol 2007;45:2819-28.

24. Dowd SE, Wolcott RD, Sun Y, McKeehan T, Smith E, Rhoads D. Polymicrobial nature of chronic diabetic foot ulcer biofilm infections determined using bacterial tag encoded FLX amplicon pyrosequencing (bTEFAP). PLoS One 2008:3:e3326.

25. Tentolouris N, Petrikkos G, Vallianou N, Zachos C, Daikos GL, Tsapogas P, et al. Prevalence of methicillin-resistant Staphylococcus aureus in infected and uninfected diabetic foot ulcers. Clin Microbiol Infect 2006;12:186-9.

26. Anandi C, Alaguraja D, Natarajan V, Ramanathan M, Subramaniam CS, Thulasiram M, et al. Bacteriology of diabetic foot lesions. Indian J Med Microbiol 2004;22:175-8.

27. Hartemann-Heurtier A, Robert J, Jacqueminet S, Ha Van G, Golmard JL, Jarlier $\mathrm{V}$, et al. Diabetic foot ulcer and multidrug-resistant organisms: Risk factors and impact. Diabet Med 2004;21:710-5.

How to cite this article: Yerat RC, Rangasamy VR. A clinicomicrobial study of diabetic foot ulcer infections in South India. Int J Med Public Health 2015;5:236-41.

Source of Support: Nil, Conflicts of Interest: None declared. 